\title{
Zatorowość płucna czy ostry zespół wieńcowy - trudności diagnostyczne
}

\section{Pulmonary embolism or acute coronary syndrome - diagnostic difficulties}

\author{
Aleksandra Bieñ ${ }^{1}$, Małgorzata Krzciuk ${ }^{1}$, Agnieszka Bojarska-Junak ${ }^{2}$ \\ ${ }^{1}$ Zespół Opieki Zdrowotnej w Ostrowcu Świętokrzyskim \\ ${ }^{2}$ Katedra i Zakład Immunologii Uniwersytetu Medycznego w Lublinie
}

\section{Streszczenie}

Zatorowość płucna (PE) to zagadnienie, które mimo dostępności badań obrazowych oraz laboratoryjnych pozostaje trudnym problemem diagnostycznym. Wystąpienie choroby wiąże się ze zwiększonym ryzykiem wczesnego zgonu, dlatego istotne jest wczesne zastosowanie odpowiedniego leczenia. W przebiegu PE pojawiają się typowe zmiany w zapisie elektrokardiograficznym, jednak część z nich budzi wątpliwości diagnostyczne i wymaga różnicowania z innymi stanami ostrymi, takimi jak zawał serca. Przedstawiony przypadek to przykład występowania objawów sugerujących początkowo ostry zespół wieńcowy, jednak dalsza analiza doprowadziła do rozpoznania PE jako przyczyny dolegliwości.

Słowa kluczowe: ostra zatorowość płucna, ostry zespół wieńcowy, fibrynoliza, leczenie przeciwkrzepliwe, embolektomia

Folia Cardiologica 2017; 12, 4: 386-389

\section{Wprowadzenie}

Zatorowość płucna (PE, pulmonary embolism) jest najpoważniejszą konsekwencją żylnej choroby zakrzepowo-zatorowej. Diagnostyka PE bywa trudna, dlatego że choroba przebiega często w sposób bezobjawowy, a zdarza się również, że pierwszym jej objawem jest nagły zgon sercowy. Najczęstszymi objawami sugerującymi PE są duszność, omdlenie, ból w klatce piersiowej [1, 2]. Ostatni objaw może mieć charakter dławicowy i wymaga różnicowania z ostrym zespołem wieńcowym (ACS, acute coronary syndrome). Strategie leczenia są różne w przypadku powyższych schorzeń, zatem o losach pacjenta decyduje prawidłowa i szybka diagnostyka.

\section{Opis przypadku}

Pacjentka w wieku 54 lat, z otyłością, została przyjęta na oddział kardiologii z powodu dolegliwości dławicowych oraz uczucia duszności trwających od około 2 godzin przed przyjęciem. Pacjentka była leczona z powodu choroby niedokrwiennej serca; w wywiadzie stwierdzono stan po przebytym zawale serca bez załamka Q ściany przednio-bocznej w 2008 roku, nadciśnienie tętnicze z przerostem mięśnia lewej komory, cukrzycę typu 2, zakrzepicę żył kończyn dolnych (stan po krosektomii ujścia prawej żyły odpiszczelowej), hiperlipidemie, niedoczynność tarczycy, stan po cholecystektomii.

Przy przyjęciu pacjentka pozostawała w ciężkim stanie ogólnym; stwierdzono duszność spoczynkową, tachykardię zatokową 102/min, głośne tony serca, prawidłowy szmer pęcherzykowy i ciśnienie tętnicze 155/82 mm Hg.

W zapisie elektrokardiograficznym (EKG) obserwowano miarowy rytm zatokowy 96/min, pośrednią oś serca, zespół S1Q3T3 oraz uniesienie odcinka ST-T w odprowadzeniach III, aVF i obniżenie odcinka ST-T w odprowadzeniach I, aVL (ryc. 1). Badania laboratoryjne wykazały: wzrost stężeń troponiny T oznaczonej metodą wysokoczułą

Adres do korespondencji: lek. Aleksandra Bień, Zespół Opieki Zdrowotnej w Ostrowcu Świętokrzyskim, ul Szymanowskiego 11,

27-400 Ostrowiec Świętokrzyski, e-mail: aleksandrabien86@gmail.com 


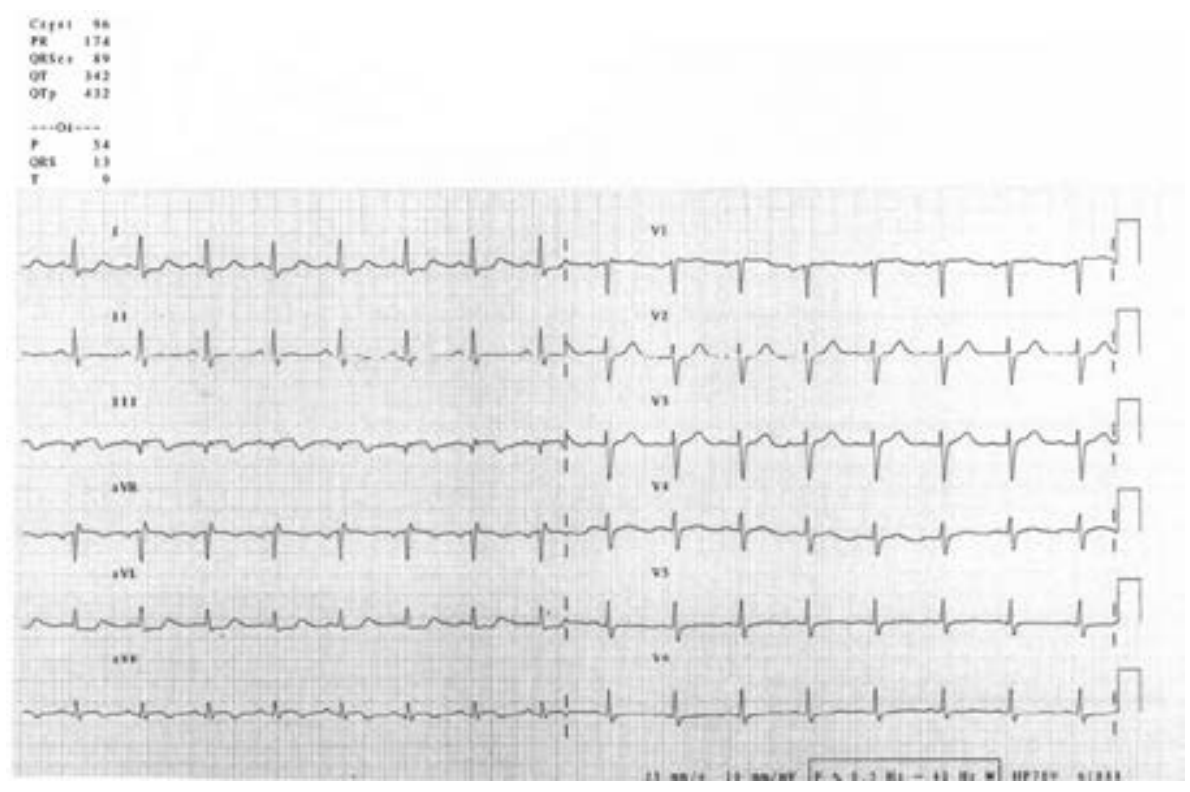

Rycina 1. Zapis elektrokardiograficzny przy przyjęciu (opis w tekście)

(hs-TnT, high-sensitivity troponin T) z 438,3 do 942,0 pg/ /ml (norma < $14 \mathrm{pg} / \mathrm{ml}$ ), kinazy kreatynowej (CK, creatine kinase) do $708 \mathrm{j} . / \mathrm{I}$ (norma 25-175 j./I) i frakcji sercowej kinazy kreatynowej (CK-MB, creatine kinase myocardial bound) do $90 \mathrm{j}$./I (norma < $25 \mathrm{j}$./l) oraz obniżoną saturację tlenu w krwi tętniczej $\left(\mathrm{SaO}_{2} 89 \%\right)$, wzrost wartości D-dimerów do $1539 \mathrm{ng} / \mathrm{ml}$ (norma < 500 ng/ml) i N-końcowego fragmentu propeptydu natriuretycznego typu $B$ (NT-proBNP, N-terminal B-type natriuretic propetide) do $1768 \mathrm{pg} / \mathrm{ml}$ (norma < $125 \mathrm{pg} / \mathrm{ml}$ ).

Ze względu na istotny wzrost wartości markerów niedokrwienia mięśnia sercowego, objawy stenokardialne oraz obraz ACS-zawału serca z uniesieniem odcinka (STEMI, ST-elevation myocardial fraction) w EKG pacjentkę konsultowano hemodynamicznie. W trybie dyżurowym wykonano badanie echokardiograficzne (ECHO) serca, w którym obserwowano zmiany sugerujące PE (poszerzona prawa komora 4,2 cm, ciśnienie skurczowe prawej komory [RSVP, right ventricular systolic pressure] ok. $45 \mathrm{~mm} \mathrm{Hg}$ ). Pacjentkę zakwalifikowano do angiografii tomografii komputerowej (angio-CT, computed tomography angiography) tętnic płucnych, w której potwierdzono obecność materiału zatorowego (stwierdzono ubytki wypełnienia o charakterze PE zlokalizowane w podziale tętnic dolnopłatowych i prawej górnopłatowej oraz obustronnie w tętnicach segmentowych do segmentów 10 , 9, 5, 4 oraz 3. prawego płuca; ryc. 2).

U pacjentki wdrożono leczenie w warunkach sali intensywnego nadzoru kardiologicznego. Rozpoczęto tlenoterapię, a w ramach leczenia przeciwkrzepliwego zastosowano riwaroksaban w dawce $15 \mathrm{mg} 2$ razy po 1 tabletce. W trakcie hospitalizacji pacjentkę konsultował

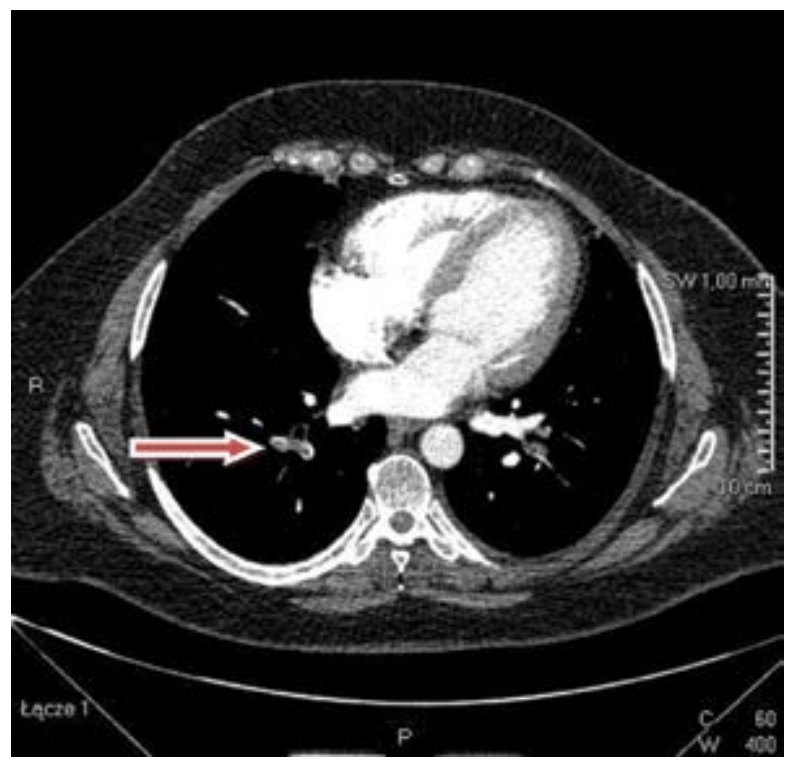

Rycina 2. Angiografia tomografii komputerowej. Ubytki wypełnienia o charakterze zatorowości płucnej w tętnicach prawego płuca (zaznaczono strzałką)

również chirurg naczyniowy, stwierdzając zakrzepicę pnia lewej żyły odpiszczelowej.

W kontrolnych badaniach laboratoryjnych wykazano poprawę saturacji krwi tętniczej $\left(\mathrm{SaO}_{2} 93,6 \%\right)$ oraz obniżenie stężeń D-dimerów (do 972 ng/ml) i hs-TnT (do 461,0pg/ml). Natomiast w kolejnych zapisach EKG obserwowano miarowy rytm zatokowy 60/min, pośrednią oś serca oraz zespół QS w odprowadzeniu III i ujemne załamki T w odprowadzeniach II, III, aVF, V4-V6 (ryc. 3). 


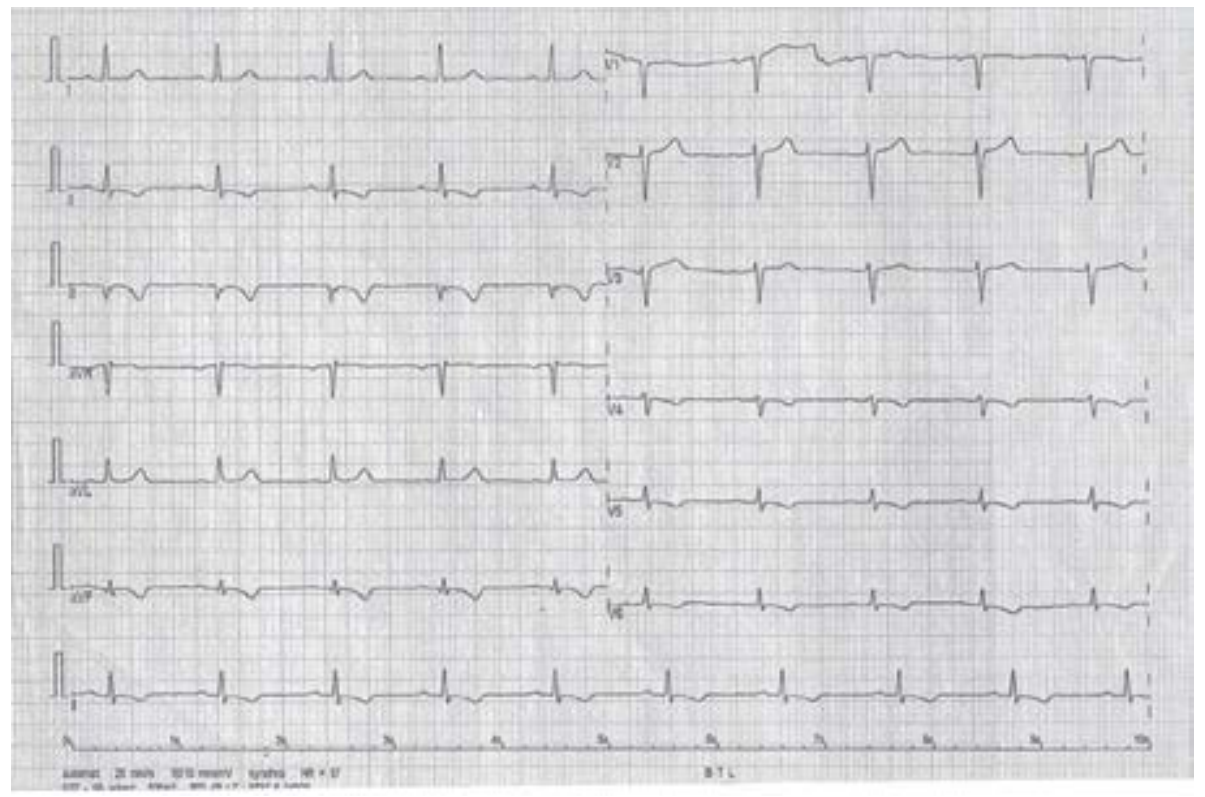

Rycina 3. Zapis elektrokardiograficzny przy wypisaniu (opis w tekście)

Podczas pobytu pacjentki na oddziale kardiologii wykonano ponowne przezklatkowe badanie ECHO serca, w którym uwidoczniono: nieco poszerzony lewy przedsionek $(4,1 \mathrm{~cm})$, prawą komore $(3,7 \mathrm{~cm})$ o zachowanej kurczliwości, aortę wstępującą o średnicy $3,7 \mathrm{~cm}$ i pogrubiały mięsień lewej komory - przegroda międzykomorowa grubości 1,4 cm. Nie uwidoczniono odcinkowych zaburzeń kurczliwości lewej komory. Frakcja wyrzutowa wynosiła $65 \%$. Stwierdzono niedomykalność mitralną I/II stopnia (MR, mitral regurgitation) ERO około $0,18 \mathrm{~cm}^{2}$, RSVP około $25 \mathrm{~mm} \mathrm{Hg}$, pień płucny o średnicy $2,5 \mathrm{~cm}$, gałęzie pnia płucnego o średnicy $1,7 \mathrm{~cm}$, czas akceleracji - przyspieszenia przepływu przez zastawke tętnicy płucnej (AccT PV, acceleration time pulmonary valve) - około 135 ms, śladowa separacja blaszek w osierdziu.

\section{Dyskusja}

W celu rozpoznania PE należy ocenić prawdopodobieństwo choroby na podstawie oceny klinicznej oraz po zastosowaniu skali Wellsa lub genewskiej (schemat trzypoziomowy - prawdopodobieństwo niskie, pośrednie i wysokie lub schemat dwupoziomowy - PE mało prawdopodobna lub prawdopodobna). W diagnostyce PE wysokiego prawdopodobieństwa ma zastosowanie angio-CT, natomiast w przypadku PE niskiego, pośredniego prawdopodobieństwa - oznaczenie D-dimerów. Niskie stężenie D-dimerów pozwala wykluczyć PE, natomiast wysokie wymaga dalszej diagnostyki za pomocą angio-CT. Strategia leczenia zatoru płucnego wysokiego ryzyka uwzględnia zastosowanie leczenia trombolitycznego rekombinowanym tkankowym aktywatorem plazminogenu, natomiast w przypadku pośredniego i niskiego ryzyka - leczenia przeciwkrzepliwego $[3,4]$. U pacjentów, u których fibrynoliza jest przeciwwskazana lub nieskuteczna, stosuje się embolektomię chirurgiczna. Zabieg ten wiąże się z niższym ryzykiem niż kolejna próba leczenia fibrynolitycznego [5].

U opisywanej pacjentki występowało kilka czynników ryzyka PE: wiek ponad 40 lat, otyłość, przebyta żylna choroba zakrzepowo-zatorowa. Na podstawie skali prawdopodobieństwa Wellsa, a także zmian w badaniu ECHO serca (cechy dysfunkcji prawej komory) oraz wzrostu wartości NT-proBNP i hs-TnT pacjentke zakwalifikowano do grupy pośredniego ryzyka i zastosowano leczenie przeciwkrzepliwe riwaroksabanem.

Przypadek pacjentki wymagał różnicowania z ACS ze względu na objawy dławicowe, obecne zmiany w zapisie EKG (uniesienie odcinka ST-T) oraz wzrost wartości markerów niedokrwienia mięśnia sercowego. Natomiast wykonane badanie ECHO serca sugerowało zmiany charakterystyczne dla PE, co potwierdzono $w$ badaniu angio-CT.

Elektrokardiografia jest prostym badaniem, na podstawie którego można wysunąć podejrzenie PE. W przebiegu choroby obecne są charakterystyczne zmiany w zapisie EKG, takie jak tachykardia zatokowa, objaw McGinna-White'a (załamek S w odprowadzeniu I, załamek Q w odprowadzeniu III, ujemny załamek T w odprowadzeniu III), ujemne załamki T w odprowadzeniach V2-V4, obniżenie odcinka ST-T w odprowadzeniach V4-V6, uniesienie odcinka ST-T w odprowadzeniach III, V1, aVR, objaw Kuchera ( $\mathrm{RR}, \mathrm{QR}$ w odprowadzeniu V1), niezupełny lub zupełny blok prawej odnogi pęczka Hisa (RBBB, right bundle branch block). Obecność w zapisie EKG części z powyższych zmian 
wiąże się ze wzrostem śmiertelności w przebiegu choroby. Najsilniejszy związek z ryzykiem zgonu mają zmiany odcinka ST-T (zarówno uniesienie, jak i obniżenie), objaw S1Q3T3 oraz RBBB [6].

W celu rozpoznania ACS należy, oprócz wzrostu wartości biomarkerów niedokrwienia mięśnia sercowego, wziąć także pod uwage jedno z poniższych kryteriów: objawy stenokardialne, znamienne zmiany odcinka ST-T lub patologiczne załamki Q w zapisie EKG, zaobserwowane zaburzenia kurczliwości w badaniu ECHO serca lub zwężenie światła tętnicy wieńcowej w badaniu angiograficznym [7].

\section{Podsumowanie}

Strategie leczenia ACS oraz PE znacznie się różnią. W przypadku ACS najczęstszym leczeniem z wyboru jest zastosowanie strategii inwazyjnej, natomiast PE w głównej mierze leczy się zachowawczo, dlatego też istotne są szybka diagnostyka oraz zastosowanie odpowiedniego postępowania.

\section{Konflikt interesów}

Autorki nie zgłaszają konfliktu interesów.

\section{Abstract}

Despite the availability of imaging and laboratory tests, pulmonary embolism remains a difficult diagnostic problem. The disease is associated with an increased risk of an early death and for this reason, it requires prompt treatment. There are some ECG changes that are typical for pulmonary embolism, but some of them need to be differentiated with other acute conditions, such as myocardial infarction. This case report presents a patient with symptoms suggesting acute coronary syndrome, finally diagnosed with pulmonary embolism.

Key words: acute pulmonary embolism, acute coronary syndrome, fibrinolysis, anticoagulant therapy, embolectomy

Folia Cardiologica 2017; 12, 4: 386-389

\section{Piśmiennictwo}

1. Cohen AT, Agnelli G, Anderson FA, et al. VTE Impact Assessment Group in Europe (VITAE). Venous thromboembolism (VTE) in Europe. The number of VTE events and associated morbidity and mortality. Thromb Haemost. 2007; 98(4): 756-764, indexed in Pubmed: 17938798.

2. Stein PD, Henry JW. Prevalence of acute pulmonary embolism among patients in a general hospital and at autopsy. Chest. 1995; 108(4): 978-981, indexed in Pubmed: 7555172.

3. Ludwik B, Lewczuk J, Piszko P, et al. [Normal coronary angiogram in patient with diagnosis of acute coronary syndrome with ST segment elevation. Was it possible to recognise acute pulmonary embolism earlier?]. Kardiol Pol. 2006; 64(1): 68-71, indexed in Pubmed: 16444636.

4. Konstantinides SV, Torbicki A, Agnelli G, et al. Task Force for the Diagnosis and Management of Acute Pulmonary Embolism of the European Society of Cardiology (ESC). 2014 ESC guidelines on the diag- nosis and management of acute pulmonary embolism. Eur Heart J. 2014; 35(43): 3033-0069, 3069a-3069k, doi: 10.1093/eurheartj/ /ehu283, indexed in Pubmed: 25173341.

5. Meneveau N, Séronde MF, Blonde MC, et al. Management of unsuccessful thrombolysis in acute massive pulmonary embolism. Chest. 2006; 129(4): 1043-1050, doi: 10.1378/chest.129.4.1043, indexed in Pubmed: 16608956.

6. Daniel KR, Courtney DM, Kline JA. Assessment of cardiac stress from massive pulmonary embolism with 12-lead ECG. Chest. 2001; 120(2): 474-481, indexed in Pubmed: 11502646.

7. Mendis $\mathrm{S}$, Thygesen $\mathrm{K}$, Kuulasmaa $\mathrm{K}$, et al. Writing group on behalf of the participating experts of the WHO consultation for revision of WHO definition of myocardial infarction. World Health Organization definition of myocardial infarction: 2008-09 revision. Int J Epidemiol. 2011; 40(1): 139-146, doi: 10.1093/ije/dyq165, indexed in Pubmed: 20926369. 